\title{
Illegalities and Infirmities in Implementation of ' $E x-$ Servicemen Contributory Health Scheme: Public Audit Findings and Other Irregularities - An Analytical Study
}

\author{
Bhupal Singh ${ }^{1}$, Asha Verma ${ }^{2}$ \\ ${ }^{1}$ Ph.D. Scholar (Law), ${ }^{2}$ Professor (Ph.D. Guide), Amity Institute of Advanced Legal Studies, \\ Amity University, Noida (UP)
}

\begin{abstract}
The objective of the study is to find out the deficits in the Ex-servicemen Contributory Health Scheme (ECHS) that was introduced in 2003 by the Government of India as a panacea for all health needs of veterans' fraternity. The study also analyses these deficiencies and submit certain tangible recommendations with a view to improvise the existing health scheme which should enhance the satisfaction level of the ECHS beneficiaries availing the medical facility. The article critically examines various flaws and shortcomings in the implementation of contributory health scheme meant for retired armed forces personnel and their family members. Author focusses on the public audit findings on the performance of the healthcare scheme to evaluate the working of the medicare facility available under the health scheme.
\end{abstract}

Key words: ECHS, Health Schemes, Ex-servicemen'Health, CAG Audit

\section{Introduction}

"To save your world you asked this man to die; Would this man, could he see you now, ask why?"

Epitaph for an unknown soldier W.H. Auden, (1907-1973), Critic \& Poet from USA

Till 2002, there was no appropriate healthcare scheme for Retired Armed Forces personnel (referred hereinafter as veterans) and their family members, and they were struggling to manage their medicare after hanging their uniforms. However, certain medical facilities were available under armed forces insurance schemes which were inadequate as compared to Central Government pensioners. For want of quality healthcare, veterans were agitated and even filed Public Interest Litigation (PIL) in the Apex court to claim "full and free medicare to ex- servicemen and their dependents

\section{Corresponding Author: \\ Bhupal Singh \\ Ph.D. Scholar (Law), Amity Institute of Advanced Legal Studies, Amity University, Noida (Uttar Pradesh).Email: bhupalwalia@gmail.com}

as one of the fundamental rights guaranteed under the Constitution of India". ${ }^{1}$ Although veterans failed to obtain free medicare rights, yet during the litigation, a health scheme namely Ex-servicemen Contributory Health Scheme (ECHS) was approved by the Central Government, in April 2003, to provide comprehensive healthcare on the pattern of Central Government Health Scheme (CGHS) to all ex-servicemen and their dependents. ${ }^{2}$ The scheme is contributory and compulsory for all ex-servicemen.

Spread of ECHS: Ex-servicemen are mostly spread in villages and small towns all over the country. Presently, 353 districts of the country are covered under the health scheme which is administered with 28 regional centres and 427 ECHS polyclinics [PCs] catering approximately 56 lakhs beneficiaries. ${ }^{3}$ Fixed Medical Allowance is granted for the ex-servicemen residing in non-coverage districts. Mobile medical units are also being planned to reach out to far flung and remote areas. 2634 medical facilities have been empanelled to provide treatment and hospitalisation to the beneficiaries. Polyclinic is a primary health centre which functions as Out-Patient Department (OPD) 
for consultation, essential investigation and provision of medicines and also for referral to service hospital/ empanelled hospital for treatment and hospitalization of patients. Every year 55-60 thousand ex-servicemen add to the scheme making it a gigantic healthcare scheme and at the same time, an insurmountable challenge for the scheme's managers to run the show efficiently and satisfactorily.

Evaluation of ECHS by Public Audit: After more than 15 years of implementation of the medicare scheme, national auditor i.e. Comptroller and Auditor General of India (CAG), has decided to audit the performance of the health scheme and to examine whether ECHS was able to achieve its aims and objectives. Public audit was particularly concerned with the availability of healthcare infrastructure, patient referral procedure, payment to empanelled hospitals, supply chain of medicines to polyclinics and efficacy of Online-Bill processing system. CAG has found numerous deficiencies in the healthcare system that fails to achieve the desired results of looking after the healthcare of our veterans in their old age.

Public auditors have reviewed ECHS performance for the period of financial years 2012-13 to 2014-15 and has submitted its report to the Parliament on 22 December, 2015 under Article 151 of the Constitution. The audit report ${ }^{4}$ is based on the examinations of various activities concerning ECHS at 7 Principle/ Controllers of Defence Account, 10 Regional Centres, 22 Polyclinics, 20 ECHS cells, 15 Service Hospitals and 2 Armed Forces Medical Supply Depots (AFMSD). Such coverage entails inspection of wide spectrum of operational activities of the health scheme so as to arrive at a holistic conclusion.

\section{Methods and Material}

CAG report [ No. 51 of 2015] on ECHS performance is the primary material used in the analysis. Report [No.5] of Departmentally-Related Parliamentary Standing Committee on Defence (2019-20) which examined the budgetary estimates of the health scheme for the year 2020-2021 was also scrutinised. Origin of the ECHS was also traced to search the litigation behind the scheme. Parliamentary debates are also the primary data that show the valuable indicators to facilitate appraisal of the scheme. Government departments' websites were referred for information and data. Annual report (201819) of Ministry of Defence has also been studied and utilised.

Descriptive research has been applied to explain and describe 'is' aspects of the health scheme that has facilitated to reach at 'ought to be' factors. Inductive approach has also been utilised to arrive at conclusions. Health scheme has been evaluated and analysed specifically with normative perspective.

\section{Discussion}

Smart health cards: Various flaws were found in the ECHS implementation which resulted into financial loss to the exchequer and low-level satisfaction amongst beneficiaries. Against the essence of the health scheme sanction, veterans were charged money for smart-cards without Government's approval while they were required only to pay membership fee of the health scheme at the rate applicable to the rank in which they had retired. Rs. 47.84 crores were collected from the beneficiaries and paid to the vendor, who manufactured 42 lakh smartcards between January 2004 to February 2015.

ECHS renewed the agreement in May 2010 for five years with the same vendor at the higher cost of Rs. 135 per card (initially it was 89.99 per card) without calling tenders. and even market rates were not verified. It burdened the beneficiaries and the health scheme financially. Presently, cost is Rs.177 per smart-card which ECHS beneficiaries have to bear unlike CGHS beneficiaries who are not required to pay for their healthcards. ECHS members have paid twice for cards as the health scheme has undergone technical upgradation for converting initial smart-cards to $64 \mathrm{~kb}$ smart cards.

Multiple and ineligible enrollment: Use of multiple cards by the same Ex-servicemen (ESM) having different IDs were observed. Smart-card data was found to be defective and unreliable that carries risk of fraudulent payment to hospitals and treatment to unauthorised persons. Internal control mechanism to verify multiple enrollment was lacking. 7431 smartcards more than the quantity manufactured by the vendor were found extra and in circulation. It posed a risk of misuse and also resulted in extra payment of Rs6.69 lakh to the firm. Many ESM were enrolled more than once under different IDs whereas each ESM was to possess 
only one unique ID.

Excess load on polyclinics: Medical infrastructure and manpower depend on the authorised capacity of the polyclinic. Many polyclinics were found functioning beyond their authorised capacity which resulted into poor quality of medicare services due to unavailability of medical staff and infrastructure.

Benefits to ineligible dependent beneficiary. An expenditure of Rs. 1.92 lakh was incurred on the treatment of ineligible beneficiaries. Sons of ESM on attaining the age of 25 years become ineligible to avail medical facility, but 22 referrals were provided by polyclinic after the beneficiaries had attained the age of 25 years, and 14 beneficiaries had attained the age of 25 years after issue of referral but before commencement of treatment. No mechanism existed (Dec,2015) to reverify the dependency status of ineligible beneficiaries.

Expired-medicines: Life-expired medicines costing Rs. 73.44 lakhs (March 2015) were at AFMSD Delhi Cantt and Polyclinic, Lodhi Road which were required to be returned for replacement to the supplier before three months of expiry dates. This has resulted into wasteful expenditure and poor services to the beneficiaries.

Excess payment in procurement of oxygen gas: Receipt and consumption quantity of liquid oxygen found mismatch in the Army Hospital (R \& R), Delhi in the records. In the documents maintained, consumption of liquid gas was shown more than what the quantity was received that involved excess payment of Rs. 28.15 lakh to the vendor.

Diversion of ECHS medical stores: ECHS medical stores were utilised for treatment of soldiers in military hospitals. Store accounting were not maintained separately to segregate the ECHS stores, which impacts the health services adversely to the entitled ECHS beneficiaries. Army Hospital (R \& R), Delhi was found using ECHS medical store in violation of established laid down procedure. Serving personnel seeking treatment in service hospitals are not entitled to avail ECHS medical stores which is primarily meant for ECHS beneficiaries.

Medical equipments but no technician to operate: In some polyclinics, X- Ray and Ultrasound machines were authorised but there was no manpower sanction to operate such machines. Interestingly, 22 such machines for 13 polyclinics were procured knowing well that no staff would be available to operate these machines which resulted into avoidable expenditure and idling of machines in clinics. It is saddening to note such apathetic planning to run medical services.

Shortage and deployment of manpower: Persistent shortage of staff and medical officers/specialists was observed in polyclinics against authorised strength. ECHS could not fill up sanctioned posts. Recently, manpower level has improved but shortage of medical specialists and dentists still persist. Even, available manpower was deployed and utilised in irregular manner. Polyclinics' manpower was being utilised in ECHS offices against non-entitlement. Manpower from remote PCs were diverted to big cities that had adverse impact on the medicare being provided to veterans in remote areas. Technical manpower was being utilised to perform administrative duties. Lab reports were being signed by technicians at polyclinic, Delhi in violations of medical laws.

No punitive action against defaulting hospitals: Certain empanelled hospitals were found indulging in unethical practices like- unnecessary medical procedure, overbilling, medical negligence, refusal for cashless facility and higher charges from the beneficiaries. ECHS did not take punitive actions against the defaulting hospitals in conformity with MoU compromising the delivery of medical services to the beneficiaries.

Anomalies in hospital bills: Certain hospitals have raised inflated bills over the authorised package rates which were approved. Rs.1.92 crore was made to empanelled hospitals on this account. 29 empanelled hospitals under the jurisdiction of Chandigarh and Lucknow commands were paid approximately Rs.12 crore extra for not deducting $10 \%$, as per applicable rules, on use of general ward accommodation by the ECHS beneficiaries. Empanalled hospitals in Dehradun, Jabalpur, Lucknow and Varanasi were found charging more room's rent from ECHS comparing to non-ECHS patients. Fortis Hospital has charged higher rates for knee replacement for the ECHS patients in comparison to non-ECHS patients which resulted into excess payment. 
Rebate and discount on medicines: ECHS Cells at Jabalpur, Gwalior, Pune and Jodhpur failed to deduct $10 \%$ discount on Maximum Retail Price (MRP) of chemotherapy medicines supplied to ECHS beneficiaries in violations of applicable guidelines which caused avoidable loss to ECHS. Further, there was no stipulation in the MoA to provide discount on the medicines being supplied by empanelled hospitals and as a result, they were raising bills at MRP while few PCs were procuring medicines at discounted rates.

\section{Miscellaneous infirmities of the health scheme}

(a) Government had accepted in the Parliament (Nov2016) to have found 1.6 lakh ineligible beneficiaries. who have now been removed from the data. Thus, financial loss on misuse of the health facility cannot be ruled out. However, new cards are supposed to eliminate such problems before health facilities are availed by wily elements.

(b) New smart-cards are taking extremely long time for issuing to the beneficiaries. Many are struggling to get new cards for more than one year. As a result, temporary slips are issued to avail medical services. This is again an area of concern and alarm.

(c) Long queues are seen at certain polyclinics and beneficiaries are to wait for long periods at the clinics firstly for consultation and then for collection of medicines.

(d) Medicines are constantly in short supply, more so, in remote polyclinics. Government is aware about the problems and has stated to be taking remedial measures to improve the supply chains of medicines. $^{5}$

(e) Substantial shortage of budgetary allocation to the health scheme and malpractices by the empanelled hospitals.

(f) Non-renewal of MoAs by the empanelled hospitals owing to deplorable delay in clearing the bills. 407 empanelled hospitals have been stated to have declined renewal of MoAs with ECHS over a period of time. ${ }^{6}$

(g) Manpower contractualisation in administrating the health scheme is the major root cause in its poor implementation and performance.

(h) Government has lodged a FIR against the previous vendor who was engaged in manufacturing smartcards and has failed to return the data on completion of the contract. ${ }^{7}$

\section{Conclusion and Suggestion}

ECHS has been in the service of veterans' fraternity for more than fifteen years but still, has been facing multitude of problems and has yet to achieve acceptable level of satisfaction amongst beneficiaries. Health scheme is being managed by the armed forces, known for its absolute professionalism and no-lax attitude, as such ECHS needs to perform better on all parameters in delivering of medicare facility not considering CGHS as bench mark. The following suggestions emerge from the analysis of the performance audit and other infirmities for consideration in the improvement of the health scheme.

(a) Technology should be extensively used at every stage and process of ECHS to reduce human intervention in delivering the services. Polyclinics should have emails and mobile numbers of all veterans/beneficiaries for faster communication of relevant information through emails/SMS.

(b) Payment of empanelled hospitals' bills well in time is sine que non to run the scheme effectively.

(c) Beneficiaries should be able to take appointment with doctors through a 'specialised app' and or web-based system to avoid crowds in polyclinics and better queue management.

(d) Spare capacity of service hospitals should be readily available on-line to the polyclinics so that beneficiaries can avail service hospital facilities as many polyclinics are co-located in the premises of the service hospitals.

(e) Polyclinics handling more beneficiaries than the authorised capacity be upgraded urgently, and till upgradation of polyclinic is achieved in all respect, manpower from polyclinic having low footfall, should be shifted to big polyclinic. But such manpower must be deployed for managing the health services in polyclinics.

(f) ECHS should be managed with regular manpower like CGHS on whose edifice this health scheme was envisaged. Policy framework for manpower contractulisation to manage such a huge health scheme is conceptually flawed. Reasons for engaging staff on contract are indefensible as staff requirement is of perennial nature. Contractual staff, being vulnerable in many aspects due to their service conditions, cannot be expected to provide first-rate medicare. 
(g) Salary of medical specialists/ paramedical staff must be fixed considering the market trends to fill up the vacant posts. Polyclinics should be empowered to engage local doctors on the hourly-basis till medical specialists/dental specialists are recruited as polyclinics are expected to be well acquainted with local market.

(h) Super Specialist Hospital exclusively for veterans' fraternity should be established in few states depending on the ESM numbers. It would reduce the complete dependency on the private hospitals and in due course of time, would be 'special medicare centers' for veterans in the country.

(i) Full budgetary support would be essential as the health scheme is fully financed by the Government. Bills of empanelled hospitals for an amount of Rs. 1900 crore are still pending as on February, 2020.

(j) Shortage of medicines at all polyclinics should be managed by appointing local pharmacists on the pattern of CGHS and till local pharmacists are appointed, beneficiaries should be reimbursed the cost of medicines purchased from the market.

(k) Preventive health check of beneficiaries of 50 years and above, should be carried out yearly to detect medical ailments well in time. Health Melas/ lectures by medical specialists on preventive healthcare should be organised in polyclinics and service hospitals.

\section{Conflict of Interest: Nil}

\section{Source of Funding: Self}

Ethical Clearance: was taken from Amity Institute of Advanced Legal Studies, Amity University, Noida (UP)

\section{References}

1. Confederation of Ex-servicemen Associations and Others v. Union of India and Others (2006) AIR(SC) 2945

2. Department of Ex-servicemen and Welfare, Government of India. About ECHS Ex-Servicemen
Contributory Health Scheme [Internet]. New Delhi: Government of India; 2020 [updated 2020 March 17; cited 2020 May 22]. Available from: http:// desw.gov.in/ex-servicemen-contributory-healthscheme/about-echs

3. Departmentally Related Parliamentary Standing Committee on Defence (2019-20) 17 $7^{\text {th }}$ Lok Sabha., Demands for Grants (2020-2021) Ministry of Defence. New Delhi: Lok Sabha; 2020. 246 p. Report No.: 5 .

4. Comptroller and Auditor General of India. Performance Audit on Implementation of Exservicemen Contributory Health Scheme, Union Government (Defence Services-Army). New Delhi: Comptroller and Auditor General of India, 2015. 78 p. Report No.: 51.

5. Official Debates of Rajya Sabha [ Internet]. New Delhi: Rajya Sabha. 2019. Session No.249. 2019 July 8. Unstarred Question No.1596 by Shri Rajeev Chandrasekhar, Shortage of medicines at ECHS polyclinics; [ cited 2020 March 19]; [ about 2 screens]. Available from: http://164.100.47.5/ Official_Debate_Nhindi/Floor/249/F08.07.2019. pdf

6. Geeta. Functional Irregularities Haunt the ECHS scheme. Medical Dialogues - Daily Dose of Health and Medical News [ internet]. 2016 Mar 9 [cited 2020 Mar 10]; Editor's pick: [about 3p.]. Available from: https://medicaldialogues. in/functional-irregularities-haunt-the-echsscheme?infinitescroll=1

7. Press Trust of India. Defence ministry alleges company not returning data of 45 lakh exservicemen. Hindustan Times (New Delhi) [Internet]. 2019 December 30 [ cited 2020 March 20]; India News: [about 4p.]. Available from: https://www.hindustantimes.com/indianews/defence-ministry-alleges-company-notreturning-data-of-45-lakh-ex-servicemen/storyKBYxUwc1sBXHv6BdAFjzCJ.html 